\title{
Cultivated Mushrooms in Malawi: A Look at the Present Situation
}

\author{
Alfred Chioza, Shoji Ohga \\ Department of Agro-Environmental Sciences, Faculty of Agriculture, Kyushu University, Fukuoka, Japan \\ Email: hachioza@yahoo.com, ohga@forest.kyushu-u.ac.jp
}

Received November 23, 2013; revised December 23, 2013; accepted December 30, 2013

Copyright (c) 2014 Alfred Chioza, Shoji Ohga. This is an open access article distributed under the Creative Commons Attribution License, which permits unrestricted use, distribution, and reproduction in any medium, provided the original work is properly cited. In accordance of the Creative Commons Attribution License all Copyrights (C) 2014 are reserved for SCIRP and the owner of the intellectual property Alfred Chioza, Shoji Ohga. All Copyright (C) 2014 are guarded by law and by SCIRP as a guardian.

\section{ABSTRACT}

This paper presents the status of mushroom cultivation in Malawi. This is a developing country located in southeastern Africa between latitudes $9^{\circ} 25^{\prime}$ South and $17^{\circ} 08^{\prime}$ South and longitudes $33^{\circ}$ East and $36^{\circ}$ East. Almost all the mushroom cultivators in the country are growing Pleurotus ostreatus. This species is most preferred because of its easiness to cultivate using the low-cost cultivation method being practiced in the country. On average, the annual $P$. ostreatus production is estimated at $240 \mathrm{~kg}$ per grower. Mushroom cultivators are selling their produce at prices ranging from MK800 (USD2.04) to MK2000 (USD5.10) per kg. At present, there are four institutions that are producing spawn namely Bunda College (Lilongwe University of Agriculture and Natural resources), Bvumbwe Agricultural Research Station, Natural Resources College and the Biology Department at Chancellor College, University of Malawi. Currently, a total of about 1307 bottles (330 ml each) of $P$. ostreatus spawn are sold by these four spawn producers per month. Mushroom cultivation is not that popular in Malawi. This may be, partly, attributed to lack of know-how and awareness on the economic, nutritive and medicinal benefits of cultivated mushrooms. Some of the major supermarkets do sell Agaricus bisporus mushrooms which are imported from the Republic of South Africa. They also sell Pleurotus ostreatus sourced from local cultivators.

\section{KEYWORDS}

Agaricus bisporus; Cultivated Mushrooms; Malawi; Pleurotus ostreatus

\section{Introduction}

Malawi is a developing country located in south-eastern Africa between latitudes $9^{\circ} 25^{\prime}$ South and $17^{\circ} 08^{\prime}$ South and longitudes $33^{\circ}$ East and $36^{\circ}$ East. Most people in Malawi have known and used wild edible mushrooms as food since time immemorial. These wild edible mushrooms are seasonal, available only during the rainy season (November to March). Outside this season, some dried mushrooms can be available in some local markets, especially in the four cities of the country. Most wild edible mushrooms in Malawi are collected from Miombo woodlands and they include Chantarelles, Lactaria and Russula species. While wild edible mushrooms are popular, most people are not familiar with cultivated mushrooms. This could be attributed to limited availability and lack of awareness on the economic, nutritional and medicinal benefits of cultivated mushrooms. Only a hand- ful of cultivators are present in Malawi. At the moment, it is the oyster mushroom, Pleurotus ostreatus, which is being commercially cultivated by almost all the mushroom farmers. Button and oyster mushrooms are available in some major supermarkets. Almost all of the button mushrooms available in Malawi at the moment are imported, mainly from the Republic of South Africa. Button mushrooms have by far the biggest commercial demand in southern Africa, but their production by small-scale farmers is not easy because they require low temperatures and highly selective and complex substrates resulting from composting [1].

As reported in Gwanama et al. [1], Africa produces very small quantities of cultivated mushrooms, less than $1 \%$ of the world's total tonnage. Most of this production is in South Africa. However, Malawi and the rest of Africa have high potential for widespread production because 
of availability of abundant materials from agriculture wastes that could be used for mushroom production. All that is needed is to popularize this crop and build capacity in the art of mushroom farming. With mushroom cultivation, ordinary people from communal areas, periurban dwellers and commercial farmers can earn considerable income and employ many others [1]. Mushroom is considered as one of the important food items since ancient time and its consumption continues to increase for its significant role in human health, nutrition and diseases [2]. A number of mushrooms are reported to have medicinal properties. Popular medicinal macrofungi include Ganoderma lucidum, Ophiocordyceps sinensis, Lentinula edodes (Shiitake), Antrodia cinnamomea, Grifola frondosa (Maitake), Agaricus blazei and Inonotus obliquus. Some of the most recently isolated and identified compounds originating from the medicinal mushrooms have shown promising immunomodulatory, antitumor, cardiovascular, antiviral, antibacterial, antiparasitic, hepatoprotective and antidiabetic properties [3].

In spite of the potential of mushroom growing in improving livelihoods of people and the ease of accessibility of materials for production, mushroom cultivation in Malawi is still in its infancy. The purpose of this paper is to provide useful baseline information for any upcoming initiative(s) aimed at promoting commercial mushroom cultivation in Malawi.

\section{Methodology}

The information presented in this paper was collected through review of existing documents and interviews with main actors in mushroom production in Malawi. Much of the information was obtained from the Mushroom Project at Bunda College, Natural Resources College, Bvumbwe Agricultural Research Station and the Biology Department at Chancellor College. These four are the only spawn producers in Malawi at the moment. They are also involved in providing training in mushroom production. Some major supermarkets provided information on cultivated species being sold, their retail prices and countries of production.

\section{Species Cultivated}

In 2008, Mpeketula [4] reported three species as being cultivated in the country and these were Agaricus bisporus (button mushrooms), Pleurotus sajor cajor and Pleurotus ostreatus of which the Pleurotoid species (oysters) were the commonest. However, we found that almost all the cultivators are growing Pleurotus ostreatus (Figure 1) for commercial purposes. This species is most preferred among the available species because it is very easy to grow under the low-tech mushroom farming being practiced in Malawi.
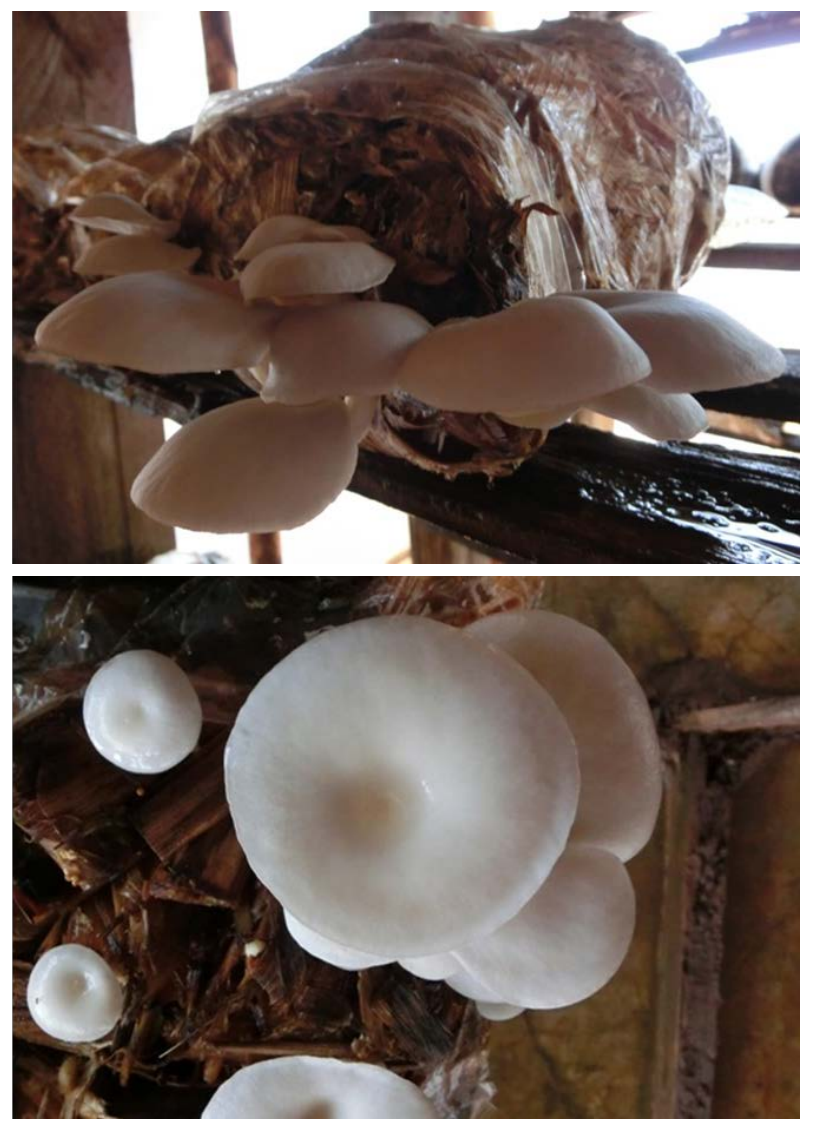

Figure 1. Pleurotus ostreatus growing in one of the mushroom houses at Bunda College, Malawi.

Despite having the largest commercial demand, we found that button mushrooms are not being commercially cultivated in Malawi. The main reason given was that these mushrooms require more advanced cultivation techniques which most growers in Malawi cannot afford. Some major supermarkets like Shoprite, City Supermarket and METRO are selling button mushrooms (Figure 2) imported from the Republic of South Africa. This ensures a readily available market for anybody wishing to venture into commercial button mushroom production in the country.

\section{Spawn Production}

Currently there are four institutions that are producing spawn and these are Bunda College (Lilongwe University of Agriculture and Natural Resources), Natural Resources College (NRC), Bvumbwe Agricultural Research Station (BARS) and the Biology Department at Chancellor College, University of Malawi. Red sorghum (Figure 3) is mostly used as substrate for spawn.

Used glass bottles of alcoholic beverages (Figure 4) are mainly used as containers for spawn. While most glass bottles of soft and alcoholic drinks are returned for reuse, bottles of ciders are not returned. That makes them 


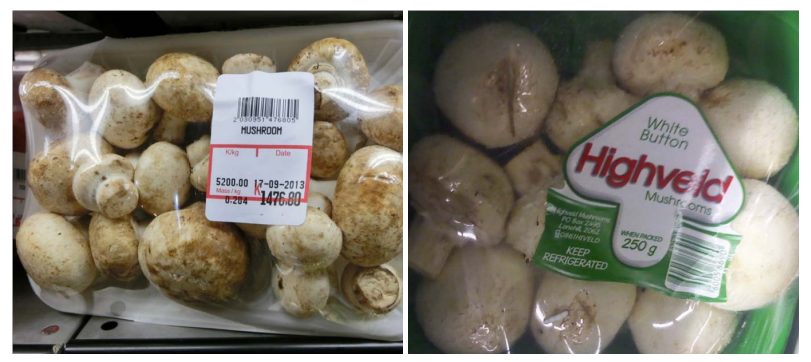

Figure 2. Agaricus bisporous (White button mushrooms) being sold in Malawi; imported from the Republic of South Africa.

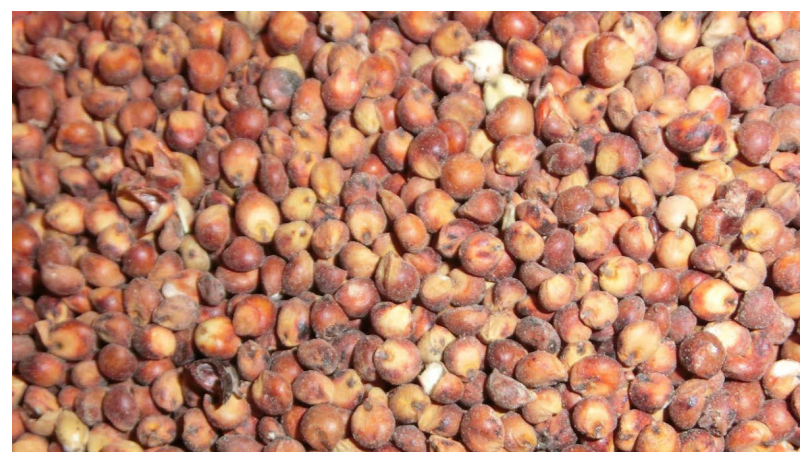

Figure 3. Red sorghum, used as substrate in oyster spawn production in Malawi.

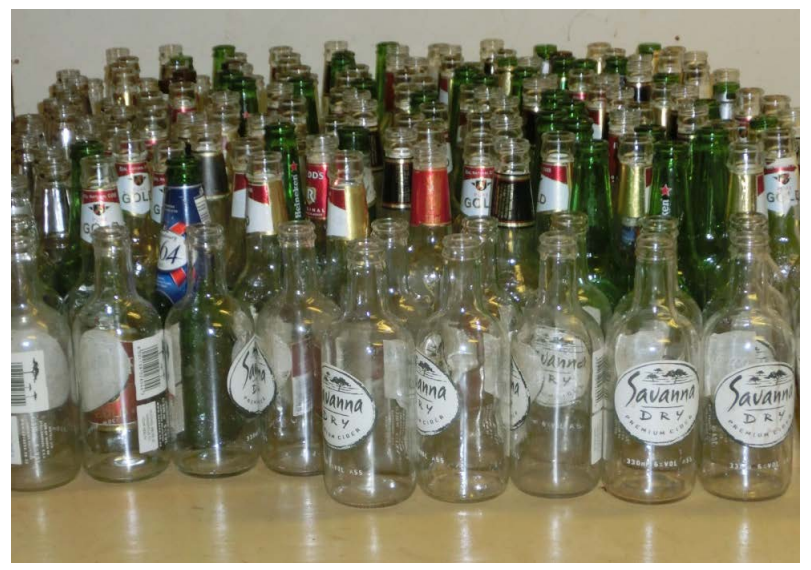

Figure 4. Used glass bottles of alcoholic beverages commonly used as containers for spawn in Malawi.

available in abundance for use in spawn production.

At the moment, a total of about 1307 bottles of P. ostreatus spawn are sold by the four spawn producers per month. The calculation on number of bottles sold is based on $330 \mathrm{ml}$ sized bottles like the ones shown in Figure 4. In cases where other types of spawn containers were used, conversion of the quantities sold to $330 \mathrm{ml}$ bottles were made. The selling prices range from MK250 (USD0.64) to MK350 (USD0.89) per $330 \mathrm{ml}$ bottle (Table 1). Spawn is commonly sold in bottles as shown in Figure $5.750 \mathrm{ml}$ glass bottles of tomato sauce are also used, especially by Bvumbwe Agricultural Research Sta-
Table 1. P. ostreatus spawn production and selling prices in Malawi.

\begin{tabular}{ccc}
\hline Spawn Producer & $\begin{array}{c}\text { Average Quantity } \\
\text { Sold per Month } \\
\text { (330 ml Bottles) }\end{array}$ & $\begin{array}{c}\text { Selling Price } \\
\text { MK (USD)/Bottle }\end{array}$ \\
\hline Bunda College, LUANAR & 300 & $350(0.89)$ \\
Bvumbwe Research Station & 505 & $264(0.67)$ \\
Chancellor College & 182 & $350(0.89)^{*}$ \\
Natural Resources College & 320 & $250(0.64)$ \\
\hline
\end{tabular}

NOTE: The Malawi Kwacha (MK) to USD conversion is based on the official middle exchange rate released by the Reserve Bank of Malawi on $15^{\text {th }}$ November, $2013($ MK392.11 $=\$ 1.00)$ [5]. ${ }^{*}$ This is a subsidized price to customers who were trained by the Mushroom Project at Chancellor College. The selling price to others is MK500 (USD1.28) per $330 \mathrm{ml}$ bottle.

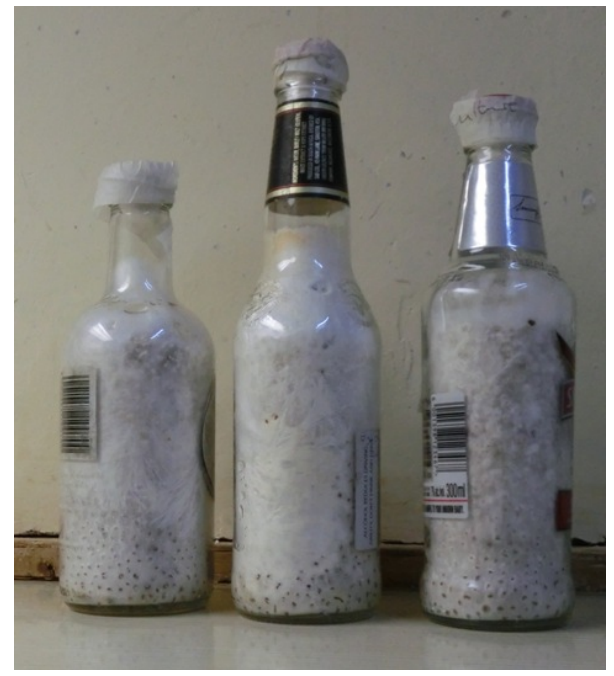

Figure 5. Fully colonised bottles of $\boldsymbol{P}$. ostreatus.

tion and Chancellor College.

Customers for spawn are small scale individual growers and community groups. There are also some nongovernmental organisations which buy spawn for promotion of mushroom production among their beneficiaries. These organisations include World Vision, Catholic Development Commission in Malawi (CADECOM), Good Neighbors, Wildlife and Environmental Society of Malawi (WESM) and Total Land Care.

Natural Resources College is promoting spawn production by lead mushroom cultivators. At the moment, there are about four lead cultivators within Lilongwe who are involved in spawn production of $P$. ostreatus. The institution gives them first generation cultures from which they produce their spawn.

\section{Cultivation Method}

Almost all mushroom cultivators in the country are using chopped maize stover as substrate. The maize stover is cut into pieces of about $3 \mathrm{~cm}$. The method presented here 
is adapted from Gwanama et al. [1].

\subsection{Substrate Preparation}

The chopped substrate in dipped in powdered soap, usually OMO or sunlight powder, and washed in a fashion similar to hand washing clothes. Then it is left to stand for five to ten minutes in the container. The substrate is then rinsed in clean water until almost all the soap bubbles have disappeared from the rinsing water. After this the substrate is packed in clean sacks or left in perforated containers overnight to drain. The moisture content is checked by squeeze test before packing in plastic growing bags. Two sizes of plastic growing bags are commonly used in Malawi and these are $8 \times 12$ and 9 $\times 14$ inches.

\subsection{Spawning}

The spawn is broken loose by shaking the bottle violently or using a disinfected wire for easy spreading on the substrate. The spawn is spread on the top surface of the substrate as shown in Figure 6. One $330 \mathrm{ml}$ spawn bottle like ones shown in Figure 5 is used to spawn fifteen to twenty $8 \times 12$ bags. Higher spawning rates than that can also be used to have quicker substrate colonisation and fruiting.

\subsection{Incubation and Fruiting}

The bags are incubated for five to six weeks before being moved to the fruiting room. In the fruiting room the substrate bags are opened and sometimes few holes are punched on the sides. These holes allow gas exchange and are also places from which mushrooms can erupt from in addition to the main opening of the bags. Generally, the spawn running phase requires high temperature, low humidity, high carbon dioxide concentration and low light intensity. The fruiting phase requires lower temperatures, more light, more oxygen and high humidity.

The mushroom houses are constructed in such a way that they provide the general conditions mentioned here. There is a wide variability in terms mushroom growing houses. Figure 7 shows a sample of some of the mushrooms houses used in Malawi.

Fruiting begins one to two weeks after moving the fully colonised growing bags into the fruiting room. The fruit bodies will keep coming from the bags, in flushes, for about three months. An experiment conducted by Natural Resources College revealed that $1 \mathrm{~kg}$ of chopped maize stover substrate is capable of producing $1.8 \mathrm{~kg}$ $1.9 \mathrm{~kg}$ of $P$. ostreatus fresh mushrooms using the simple cultivation method explained earlier. This represents a Biological Efficiency (BE) of $180 \%$ - 190\%. This is not surprising because BE of $200 \%$ can be accomplished in

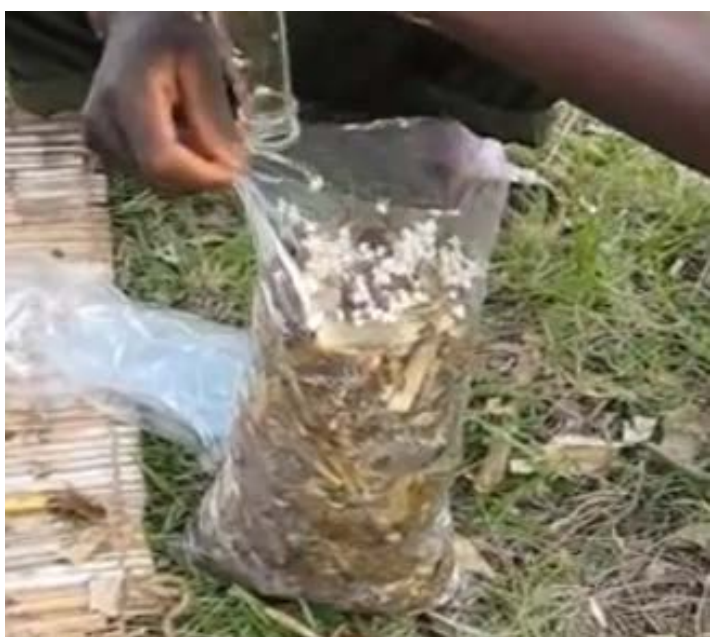

Figure 6. Inoculation of substrate with $P$. ostreatus spawn.
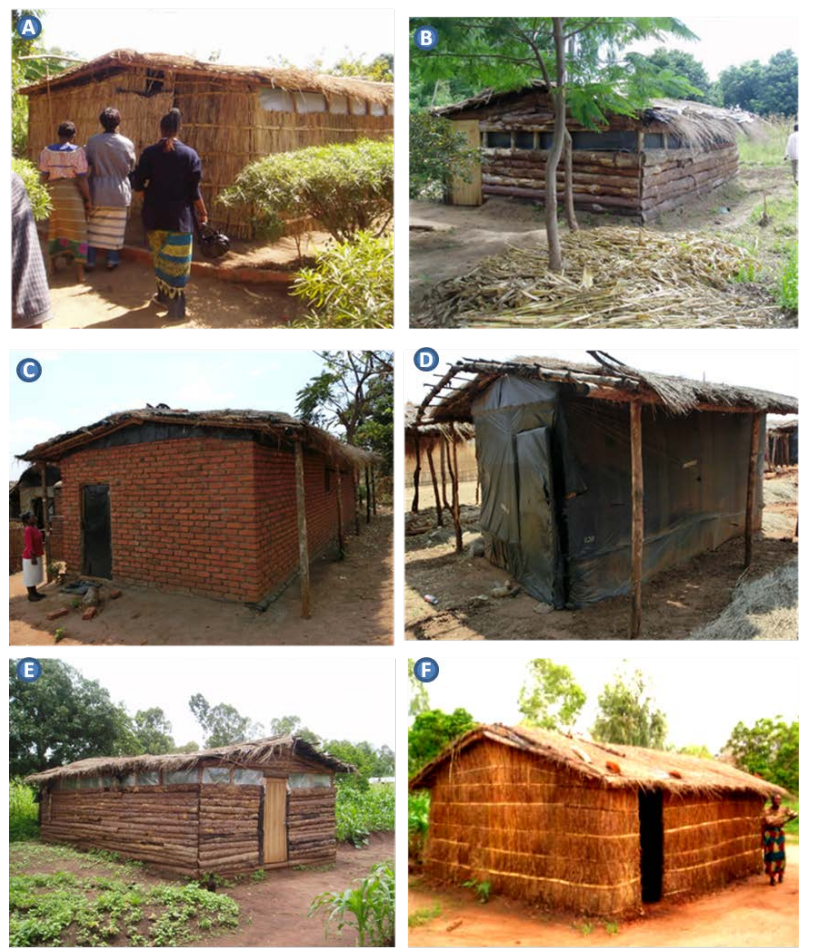

Figure 7. A sample of mushroom houses used in Malawi. Sources of photographs: (A) and (B) from the Mushroom Project at Chancellor College [8]; (C) and (D) by A. Chioza; (E) and (F) by P. M. G. Mpeketula.

Oyster cultivation as reported by Aloha Medicinals [6]. It is estimated that, on average, a single cultivator is producing $240 \mathrm{~kg}$ of $P$. ostreatus mushrooms per year [7].

\section{Marketing of Cultivated Mushrooms}

Most of the cultivated mushrooms in Malawi are used in restaurants especially of major hotels and lodges. Individuals living in proximity to mushroom cultivators also provide a market for the crop. All the major institutions 
involved in mushroom cultivation indicated that the current production does not meet the demand for mushrooms in the country. This is evidenced by the importation of most of the mushrooms being traded in the country's supermarkets.

The selling prices of oyster mushrooms, by cultivators, depend on where they are being sold. The prices range from MK800/kg (USD2.04/kg) to MK2000/kg (USD $5.10 / \mathrm{kg}$ ). Most of the major supermarkets sell button and oyster mushrooms. The former is imported from the Republic of South Africa and the later is sourced from local cultivators. Table 2 shows the current average prices of mushrooms traded by major supermarkets in Malawi.

\section{Domestication of Wild Edible Mushrooms}

We think that one of the ways to popularise mushroom cultivation in the country is to bring some of the most preferred wild edible species into artificial cultivation. The majority of people are already familiar with these mushrooms and it would be much easier to accept them than foreign cultivated species. Most of the wild edible fungi in Malawi grow in association with Miombo tree species. There are fears that continued loss of forests will lead to reduced yield and probably complete loss of some of the wild edible mushrooms. Success in cultivating these species will ensure their continued availability. This will also make them available in fresh state throughout the year rather than seasonal as is the case now.

There have been some efforts in the past to bring these wild species into cultivation. For instance, Mpeketula [4] managed to successfully isolate and produce pure cultures of Termitomyces letestui, Termitomyces microcarpus and Cantharellus cibarius. However, up to now no one has managed to find a way to produce the fruit bodies of any of the indigenous edible mushrooms recorded in the country. There is need for continued research efforts aimed at finding ways to bring some of the popular wild edible mushrooms into cultivation. With advancements in biotechnology and increased knowledge in mushroom cultivation, we should be able to cultivate some of these mushrooms. In 2008 Mshandete and Cuff [9] reported success in cultivation of three Tanzanian wild edible mushrooms namely Coprinus cinereus, Pleurotus flabellatus and Volvariella volvocea. Lessons can be learnt from success stories such as this one.

\section{Challenges}

There are a number of factors that affect or have potential to affect mushroom cultivation in Malawi. These factors include the following:

1) Red sorghum, which is used as medium for spawn, is not produced in abundance in Malawi. This will pose a great threat as demand for spawn increases. Chibuku
Table 2. Prices of fresh cultivated mushrooms in Malawi's major supermarkets.

\begin{tabular}{ccc}
\hline Type of Mushroom & $\begin{array}{c}\text { Average Price } \\
\text { MK (USD)/kg }\end{array}$ & Comment \\
\hline $\begin{array}{c}\text { Pleurotus ostreatus } \\
\text { (Oyster mushrooms) } \\
\text { Agaricus bisporus } \\
\text { (White button) }\end{array}$ & $2150(5.48)$ & Cultivated locally \\
$\begin{array}{c}\text { Agaricus bisporus } \\
\text { (Portabellini) }\end{array}$ & $9196(23.46)$ & $\begin{array}{c}\text { Imported from } \\
\text { South Africa }\end{array}$ \\
$\begin{array}{c}\text { Agaricus bisporus } \\
\text { (Open brown) }\end{array}$ & $7596(19.38)$ & $\begin{array}{c}\text { Imported from } \\
\text { South Africa }\end{array}$ \\
\hline
\end{tabular}

NOTE: The Malawi Kwacha (MK) to USD conversion is based on the official middle exchange rate released by the Reserve Bank of Malawi on $15^{\text {th }}$ November, $2013($ MK392.11 $=\$ 1.00)$ [5].

Products Limited in Malawi also uses red sorghum for manufacturing an opaque beer called Chibuku. To make sure there is adequate supply of red sorghum for this product, the company gives out free sorghum seed to farmers who in turn will sell their produce to the company. This is a clear indication that red sorghum is in limited supply in the country.

2) The current method used for chopping maize stover is very tedious and inefficient. This is done by placing maize stover on a piece of wood or small log and use a panga knife to chop it into pieces of about $3 \mathrm{~cm}$ long. This is an area where engineers, especially agric-engineers, in the country could do something about. This would be by way of developing a simple, low-cost tool that will ease this process and improve efficiency.

3) Currently there are no well-defined markets and market channels for mushrooms. This has led to wide variations in prices cultivators sell their mushrooms. Some sell directly to consumers at very low prices because they do not have access to major supermarkets and hotels where they can fetch more for their produce. Organising mushroom growers into associations would be one major way of dealing with this challenge. Existing institutions like National Smallholder Farmers' Association of Malawi (NASFAM) and programmes such as One Village One Product (OVOP), supported by the Japan International Cooperation Agency (JICA), can be used by mushroom growing groups/associations as market channels.

4) Despite the economic, nutritional and medicinal benefits that mushrooms can offer, the government as well as non-governmental organisations in the country are giving very limited attention to mushroom production. This hinders development of the industry in the country. Government support cannot be ruled out if promotion of mushroom production is to be successful.

5) Lack of production "know-how" and awareness on economic, nutritional and medicinal benefits of culti- 
vated mushrooms is also a limiting factor to the development of mushroom production in the country. Unlike the growing of most field crops, mushroom cultivation requires some special knowledge and skills. Training on cultivation techniques should be continued and there should be more awareness on the benefits of cultivated mushrooms. This would motivate people to cultivate as well as consume more mushrooms.

\section{Conclusion}

In 2004, FAO reported nearly a hundred species of fungi that could be cultivated [10]. Today there may be even more than this number. Currently no more than two species of oysters are being cultivated, with success, in Malawi. This shows that the country is still lagging behind in mushroom cultivation. There is a need to introduce and popularize other cultivated species of mushrooms. However, in doing so the focus should be on developing lowcost production technologies that can be easily adopted in the country. Malawi has huge potential for mushroom farming because of the availability of large amounts of agricultural crop residues. There is also a high demand for mushrooms, locally as well as internationally. The country can take advantage of these factors to develop the mushroom industry. Continued research efforts to bring some of the native wild edible mushrooms to cultivation must be encouraged and supported. Wild edible fungi are well-known by the majority of Malawians and we think that they will be more willing to cultivate and consume mushrooms same or similar to what they are already familiar with.

\section{REFERENCES}

[1] C. Gwanama, V. M. Mwale and B. Nsibande, "Basic Procedures for Small Scale Production of Oyster Mushrooms," University of Namibia, 2011.
[2] B. K. Barmon, I. Sharmin, P. K. Abbasi and A. Mamun, "Economics of Mushroom (Agaricus bisporus) Production in a Selected Upazila of Bangladesh,” The Agriculturists, Vol. 10, No. 2, 2012, pp. 77-89. http://dx.doi.org/10.3329/agric.v10i2.13144

[3] J. E. Smith, N. J. Rowan and R. Sullivan, "Medicinal Mushrooms: Their Therapeutic Properties and Current Medicinal Usage with Special Emphasis on Cancer Treatments," University of Strathclyde and Cancer Research UK, 2002.

[4] P. M. G. Mpeketula, "Indigenous Mushroom Species Cultivation, Processing and Utilization for Food Security and Conservation," National Research Council of Malawi Conference Proceedings, 2008, pp. 95-108.

[5] "Reserve Bank of Malawi. Archived Official Exchange Rates,” 2013.

http://www.rbm.mw/archived xrates detailed.aspx

[6] "Aloha Medicinals. Low Cost/Low Tech Methods to Grow Mushrooms,” 2013. http://www.alohaculturebank.com/low-tech-growing.html\#

[7] Malawi National Assembly, "Daily Debates (Hansard), Second Meeting-Forty-Fourth Session, Thirty First Day Friday,” Serial No. 031, 2013, p. 1301.

[8] "Mushroom Project at Chancellor College, University of Malawi. Pictorial Highlights by the Spawn Laboratory," 2013.

http://www.chanco.unima.mw/localwebs/bio/mushroom/g allery.html

[9] A. M. Mshandete and J. Cuff, "Cultivation of Three Types of Indigenous Wild Edible Mushrooms: Coprinus cinereus, Pleurotus flabellatus and Volvariella volvocea on Composted Sisal Decortications Residue in Tanzania," African Journal of Biotechnology, Vol. 7, No. 24, 2008, pp. 4551-4562.

[10] Food and Agriculture Organization of the United Nations (FAO), "Wild Edible Fungi: A Global Overview of Their Use and Importance to People, by E. Boa," Non-Wood Forest Products, No. 17, 2004, p. 20. 